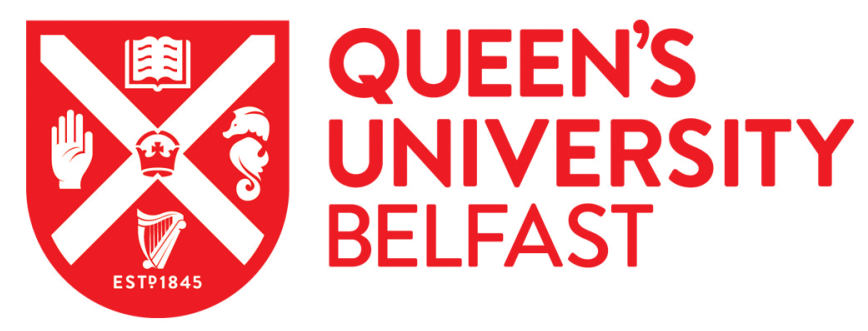

\title{
NiTi shape memory alloy with enhanced wear performance by laser selective area nitriding for orthopaedic applications
}

Ng, C. H., Chan, C. W., Man, H. C., Waugh, D. G., \& Lawrence, J. (2017). NiTi shape memory alloy with enhanced wear performance by laser selective area nitriding for orthopaedic applications. Surface and Coatings Technology, 309, 1015-1022. https://doi.org/10.1016/j.surfcoat.2016.10.042

Published in:

Surface and Coatings Technology

Document Version:

Peer reviewed version

Queen's University Belfast - Research Portal:

Link to publication record in Queen's University Belfast Research Portal

Publisher rights

(c) 2016 Elsevier B.V. All rights reserved. This manuscript version is made available under the CC-BY-NC-ND 4.0 license

$\mathrm{http}: / /$ creativecommons.org/licenses/by-nc-nd/4.0/ which permits distribution and reproduction for non-commercial purposes, provided the author and source are cited.

\section{General rights}

Copyright for the publications made accessible via the Queen's University Belfast Research Portal is retained by the author(s) and / or other copyright owners and it is a condition of accessing these publications that users recognise and abide by the legal requirements associated with these rights.

Take down policy

The Research Portal is Queen's institutional repository that provides access to Queen's research output. Every effort has been made to ensure that content in the Research Portal does not infringe any person's rights, or applicable UK laws. If you discover content in the Research Portal that you believe breaches copyright or violates any law, please contact openaccess@qub.ac.uk. 


\section{Accepted Manuscript}

NiTi shape memory alloy with enhanced wear performance by laser selective area nitriding for orthopaedic applications

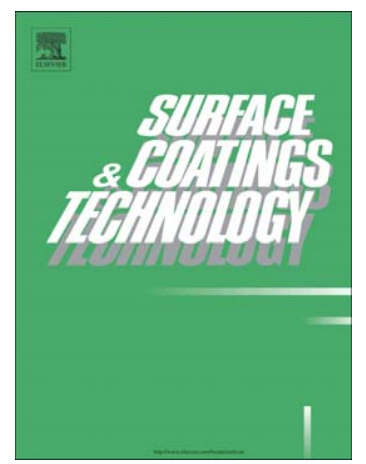

PII:

DOI:

S0257-8972(16)31038-6

Reference: $\quad$ SCT 21687

To appear in: $\quad$ Surface \& Coatings Technology

Received date: 5 July 2016

Revised date: $\quad 12$ October 2016

Accepted date: 14 October 2016

Please cite this article as: C.H. Ng, C.W. Chan, H.C. Man, D.G. Waugh, J. Lawrence, NiTi shape memory alloy with enhanced wear performance by laser selective area nitriding for orthopaedic applications, Surface \& Coatings Technology (2016), doi: $10.1016 /$ j.surfcoat.2016.10.042

This is a PDF file of an unedited manuscript that has been accepted for publication. As a service to our customers we are providing this early version of the manuscript. The manuscript will undergo copyediting, typesetting, and review of the resulting proof before it is published in its final form. Please note that during the production process errors may be discovered which could affect the content, and all legal disclaimers that apply to the journal pertain. 
NiTi shape memory alloy with enhanced wear performance by laser selective area nitriding for orthopaedic applications

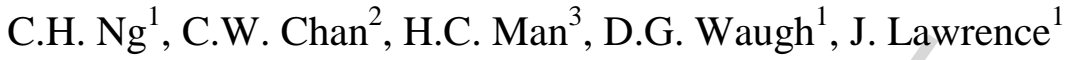 \\ ${ }^{1}$ Laser Engineering and Manufacturing Research Centre, Faculty of Science and \\ Engineering, University of Chester, Parkgate Road, Chester, CH1 4BJ, UK. \\ ${ }^{2}$ School of Mechanical and Aerospace Engineering, Queen's University, Belfast, BT9 5AH, \\ UK. \\ ${ }^{3}$ Department of Industrial and Systems Engineering, The Hong Kong Polytechnic \\ University, Hong Kong, China.
}

\begin{abstract}
In recent years, near-equiatomic NiTi alloy has been identified as a sound alternative to replace the conventional Ti6Al4V alloy as the next generation orthopaedic biomaterial because of its lower young modulus and unique shape memory effect. The potential problem of using NiTi alloy is the generation of Ni-rich debris when wear occurs. Surface treatment is therefore needed to improve the wear resistance in order to alleviate the impact of the wear. This paper details the surface treatment of NiTi by laser selective area nitriding for enhancing the wear resistance. This was done by a systematic two-step optimization approach: (1) selecting the appropriate set of laser parameters with an L9 Taguchi experiment to optimize the nitride properties and (2) identifying the optimized surface coverage ratio to maximize the wear resistance. The microstructure and surface profiles of the optimized nitride surface was characterized by scanning electron microscopy (SEM) and X-ray diffraction (XRD), and 3-D profile measurement, respectively. The wear resistance of nitrided surfaces with different coverage ratios were then evaluated using reciprocating wear testing against ultra-high-molecular-weight polyethylene (UHMWPE) in simulated body fluid, i.e., Hanks' solution.
\end{abstract}

Keywords:

Shape memory alloys. NiTi, Laser gas nitriding, wear, Taguchi experiment

Corresponding Author:

Dr. D.G. Waugh

Laser Engineering and Manufacturing Research Centre,

Faculty of Science and Engineering

University of Chester

Parkgate Road

Chester, CH1 4BJ, UK 
Tel: +44 (0) 1244513930

Email:d.waugh@chester.ac.uk 


\section{Introduction}

Total hip and knee replacement has become one of the most common surgical treatments among elderly people [1,2]. According to the data collected on total joint replacements surgery, it is estimated that by the end of 2030, the number of total hip replacements will rise by $174 \%$ (i.e., 572,000 procedures) and total knee arthroplasties is projected to grow by $673 \%$ from the present rate (i.e., 3.48 million procedure) [1]. Comparing to the mostly used orthopaedic material, namely Ti6Al4V, in the past few decades, equiatomic NiTi alloy exhibits unique shape memory effect and lower modulus (e.g. 70-110 GPa in parent B2 austenite) which are beneficial in accelerating bone healing and reducing bone shielding effects [3].Therefore, it has been recently recommended as a potential material for joint replacement applications $[4,5]$. Although NiTi possess the desirable properties over Ti6Al4V, it is not yet used in fabricating load-bearing implants that will be subjected to wear due to the concern of its high $\mathrm{Ni}$ content, i.e., the resulting Ni-rich wear debris might invoke an inflammatory and immunological response [6]. One effective method to solve the above-mentioned problem is to create a stable and hard layer on NiTi surface. It has been reported previously in the literature that $\mathrm{NiTi}$ can react with nitrogen to form TiN layer [3, 6-8]. TiN is well known to possess excellent biocompatibility, high hardness and good corrosion resistance [9-12]. Furthermore, TiN has been accepted by the U.S. food and Drug administration for medical applications such as coatings for cardiovascular, dental prostheses and orthopaedic implants [13-15].

Various surface treatments methods to create the TiN surface film/layer have been reported such as ion implantation [16], arc ion plating [17], pulsed high-energy density plasma [18, 19], chemical vapour deposition (CVD) [20], physical vapour deposition (PVD) [21] and power immersed reaction assistant coating nitriding method [22]. Nevertheless, all of these methods have their own drawbacks, such as the workpiece needs pre-heating, or the surface nitride film can easily peel off. Regarding the pre-heating in most of these methods, the substrate bulk temperature reaches above $400{ }^{\circ} \mathrm{C}$. When the temperature is too high, phase changes will take place and cause undesirable effects on the mechanical properties of the NiTi implants. In addition, the coatings that are formed on the whole surface are brittle [23]. Another disadvantage is that the depth of the coatings layer is restricted by the diffusivity of the nitrogen into the substrate. Moreover, the surface nitride film may have structure defects (i.e. pinholes, cracks and porosities) which can affect the wear performance and corrosion resistance of NiTi. With this in mind, laser gas nitriding (LGN) is an attractive method to create a TiN layer on NiTi surface. It can form an atomically intermixed layer between metallic substrate and TiN without causing over-heating in the substrate, i.e., only the surface of limited depth is heated by laser. It can also eliminate the peel-off problems because the TiN is metallurgically bonded with the substrate [24]. 
The typical depth of nitrided surface layers can be created from a few microns to a few hundred microns which depends on the type of laser. Since the first work of LGN on NiTi reported by Man et al. [7], the progress in the field has been impeded because of (1) the undesirable changes in surface roughness after LGN and (2) the re-melting of the previously-formed nitride track during the nitriding process. In the LGN, a fully-covered nitride surface is created by overlapping the laser beam with the adjacent previously-irradiated region, and thus, re-melting of the previously-formed nitride track is inevitable. Re-melting might result in a nitride layer with inhomogeneous mechanical properties between nitride tracks because mechanical properties of the nitride layer is strongly dependent on the melting conditions [24]. Until recently, an improved version of LGN method called laser diffusion nitriding is recently developed by the present authors [8]. In this method, surface roughening due to surface melting is avoided via carefully selecting the laser processing parameters in low energy regime. However, the problem of re-treating the previously-formed nitride track during the laser nitriding process is still there.

Laser diffusion nitriding on NiTi is still a new technique in the development stages. As a result, within this work, a systematic two-step optimization approach was conducted to perform the diffusion nitriding on NiTi surfaces. Firstly, appropriate set of laser parameters (namely laser power, scanning speed and spot diameter) was determined by an L9 Taguchi experiment [25-27]. The design objective was to identify the optimal parameter set to create the TiN with highest aspect ratio (thickness to depth) and minimal surface roughening effect. Secondly, the idea of selective area nitriding was attempted to minimize the problem of retreating the previously-formed nitride track. This was done by selectively irradiating the NiTi surface by laser to create a surface with different coverage ratios, i.e. controlling the ratio between the nitrided and non-nitrided surfaces. The microstructure and surface profiles of the optimized nitride surface was characterized by scanning electron microscopy (SEM) and X-ray diffraction (XRD), and 3-D profile measurement, respectively. The wear resistance of nitrided surfaces with different coverage ratios were then evaluated using reciprocating wear testing against ultra-high-molecular-weight polyethylene (UHMWPE) in simulated body fluid, i.e., Hanks' solution, and the results were then compared with that of the fully covered surface.

\section{Experimental technique}

\subsection{Application of the Taguchi Experimental Design}

In this work, a Taguchi orthogonal array design L9 experiment under controlled nitrogen environment was conducted to optimise the nitriding process. The design objective was to obtain the nitride layer with maximum track width in non-melted condition. The width of 
laser-nitrided track was acquired using an image processing program: ImageJ (an image analysis software). There are many parameters related to the process of laser gas nitriding. For instances, laser power, scanning speed, beam diameter, focal distance and nitrogen gas flow rate. Among which, laser power, scanning speed and beam diameter are reported to be most influential to affect the nitride quality, and thus, they were selected as the control factors. The control factors were varied at three levels which are presented in Table 1. They were chosen based on the results of the preliminary tests, i.e., selecting the laser parameters to produce nitride tracks in the non-melted condition. Three replicates were performed for each experimental condition to ensure the repeatability.

Since the design objective was to obtain the maximum track width, the-larger-the-better signal to noise ratio $(\mathrm{S} / \mathrm{N})$ was applied in order to control the response and reduce the variance. Equation (1) is usually used to calculate the S/N ratios for the-larger-the-better [27], which enabled one to maximize the response (aspect ratio) in the present study.

$$
\mathrm{S} / N_{L}=-10 \log \left(\frac{1}{n} \sum_{i=1}^{n} \frac{1}{\mathrm{y}_{\mathrm{i}}^{2}}\right)
$$

Where $\mathrm{S} / N_{L}$ is $\mathrm{S} / \mathrm{N}$ ratio, $\mathrm{n}$ is the number of replication and $\mathrm{y}_{\mathrm{i}}$ represents the observed data. Analysis of Variance (ANOVA) is a useful statistical method associated with Taguchi experiment to determine the data variability. The effects of the laser gas nitriding parameters on the design objective were analysed by using MiniTab 17.

\subsection{Material}

A $250 \mathrm{~mm}$ x $250 \mathrm{~mm}$ NiTi plate (Ti-50.8 at\% Ni) with a thickness of $5 \mathrm{~mm}$. The NiTi was then sparked cut in the dimensions of $40 \mathrm{~mm}$ x $30 \mathrm{~mm}$ x $5 \mathrm{~mm}$ for laser nitriding experiment. Before the experiment, the surface of the plate were ground with a series of SiC paper from 120 to 1200 grits to remove the pre-existing surface oxides and to ensure surface homogeneity. The samples were then ultrasonic cleaned in ethanol bath for 10 mins, rinsed in distilled water, and dried thoroughly in a cold air stream.

\subsection{Laser Gas Nitriding Procedures}

A $100 \mathrm{~W}$ CW fiber laser (SP-100C-0013 provided by SPI and A\&P Co., Ltd, UK) with output wavelength of $1091 \mathrm{~nm}$ was used in the laser nitriding experiment. The samples were processed in a specific gas chamber containing high purity N2 gas (99.99\%). The gas flow rate was controlled at $40 \mathrm{~L} / \mathrm{min}$. 


\subsection{Selective area laser nitriding}

To control the surface coverage ratio, two different hatch patterns, namely $1 \mathrm{~mm}(\mathrm{H} 1)$ and 3 $\mathrm{mm}(\mathrm{H} 3)$ between the nitride tracks were used in the nitriding process. The laser scanning patterns are shown in Figure 1. The nitrided surface with different hatch pattern was captured by an optical microscope and the total nitrided area was then measured by using ImageJ (see Figure 2b).

\subsection{Microstructural Analysis}

Standard metallurgical procedures were used to prepare samples for microstructure analysis. The cross-section of samples were polished with $1 \mu \mathrm{m}$ diamond paste for 5 minutes and the surface was swabbed by the etching reagent ( $\mathrm{HF} 10 \%, \mathrm{HNO}_{3} 40 \%, \mathrm{H}_{2} \mathrm{O} 50 \%$ ) within 15 seconds. The cross-sectional microstructure was captured by scanning electron microscope (SEM, JEOL Model JSM-6490, USA) and the phase of the surface nitride was identified by X-ray diffraction (XRD, Bruker D8 Advance, USA)

The parameters were set at $40 \mathrm{kV}$ and $25 \mathrm{~mA}$ using $\mathrm{Cu} \mathrm{K \alpha}$ radiation with a scanning rate of $1^{\circ}$ $\mathrm{min}^{-1}$ and the range of $2 \theta$ angles was from $20^{\circ}$ to $90^{\circ}$.

\subsection{Surface Characterization}

Surface roughness $R_{a}$ of the laser-nitrided and untreated samples were measured and compared by a non-contact surface profilometery (IFM G4 System, Alicona, Austria) with surface map software. The 3D CCI profiler was set up using a $5 \mathrm{x}$ resolution probe at a working distance of $20 \mathrm{~mm}$. The set-up parameters for the 3D profile measurement are given as follows: size $=3 \mathrm{~mm} \times 4 \mathrm{~mm}$, standard implemented $=$ ISO 4287 .

\subsection{Wear Resistance}

Reciprocating wear tests were employed to evaluate the wear properties of nitride and untreated NiTi samples against UHMWPE. Linearly reciprocating pin-on-plate sliding test was performed with Hanks' solution as a simulated body fluid in the ambient environment (TE99 Universal Wear Machine, Phoenix Tribology, UK) as described previously [28]. Briefly, The nitrided and untreated plate were located on a turntable driven at a constant speed of $0.12 \mathrm{~m} / \mathrm{s}$ and UHMWPE pin was loaded at a contact stress of around $2 \mathrm{MPa}$ by means of static weights. The friction force was recorded by the computer and converted it into friction coefficient data. The average specific wear rate of UHMWPE, nitrided and untreated surface were calculated using the Archard equation [29] given in Equation (2).

$$
\text { Wear factor }\left(\mathrm{mm}^{3} \mathrm{~N}^{-1} \mathrm{~m}^{-1}\right)=\frac{\text { Volume loss }\left(\mathrm{mm}^{3}\right)}{\text { Sliding distance }(\mathrm{m}) \times \text { Load }(\mathrm{N})}
$$


The wear factors for the nitrided and untreated surfaces were obtained. The results were taken from the average of three repetitive tests with the standard deviation for comparing each type of samples. After the wear tests, the wear tracks were observed under an optical microscope were compared. All values are expressed as means \pm standard errors, and $\mathrm{P}$ value is smaller than 0.05 was considered as significant difference.

\section{Results and Discussions}

\subsection{Analysis of Variance (ANOVA)}

The width of laser-nitrided track and the $\mathrm{S} / \mathrm{N}$ ratio for nine experiments are calculated and listed in Table 2. The graphical results of different laser parameters with 3 different levels are shown in Figure 3. The maximum average $\mathrm{S} / \mathrm{N}$ ratio is the corresponding optimum parameter level to the smaller variance of the output characteristics around the desired value [27]. As a result, the largest width of laser track can be produced using the following parameter combination which are laser power at level $2(90 \mathrm{~W})$, the scanning speed at level $1(1 \mathrm{~mm} / \mathrm{s})$ and the beam diameter at level $3(2.2 \mathrm{~mm})$. The finding agreed very well with the pervious study [28]. Statistically, F test was used to observe which processing parameters have a significant effect on the responses of aspect ratio or the output characteristic [30].

Table 3 shows the results for the ANOVA analysis for the different laser parameters. It was found that both the laser power and scanning speed were the significant factors to affect the nitriding process, followed by the beam diameter. The percentage contribution of laser power and scanning speed were $30.54 \%$ and $30.29 \%$ while the beam diameter accounted for $21.68 \%$ respectively. The error contribution was $17.48 \%$ in the Taguchi experiment which was within an acceptable range. Delta statistics in Table 4 is the additional expression of the parameter importance for the response. Delta statistics measures the effectiveness of output characteristic by taking the difference between the highest average and lowest average value for each response characteristic [31]. The process parameter are ranked from highest effect to lowest effect due to the delta values. Similar to the ANOVA results, delta values of laser power and scanning speed are higher than that of the beam diameter, indicating both of them are the influencing parameter.

\subsection{Microstructure Analysis}

The cross-section SEM micrograph of TiN layer is shown in Figure 4. It shows that the thickness of the uniform TiN layer was around $1.6 \mu \mathrm{m}$. Bernard et al. [32] found that the coating with thickness around $1 \mu \mathrm{m}$ could have significant effect on $\mathrm{Ni}$ ion release reduction. The XRD patterns of the optimized laser nitrided and untreated surface are shown in Figure 5. On the untreated surface, there are no additional diffraction peaks corresponding to intermediate precipitations, namely $\mathrm{Ni}_{3} \mathrm{Ti}$ and $\mathrm{Ni}_{4} \mathrm{Ti}_{3}$. The untreated NiTi only consists of the 
NiTi (B2) phase which is also known as the austenite phase. So the major component of the untreated NiTi was austenite at room temperature. TiN peaks are present in the patterns for the laser nitrided surface, it is an evidence of the TiN formation on the NiTi surface. This peak corresponds to cubic titanium nitride (TiN) at 200 and 311. It indicates the laser gas nitriding process does not affect the phase composition of NiTi substrate due to the absence of any intermediate precipitations XRD patterns. Also, the intensity of diffraction peaks of NiTi (B2) phase are suppressed.

\subsection{Surface Profile Analysis}

In the present study, the variations in surface roughness become less apparent when comparing with the polished sample (Figure 6a) with the laser nitrided samples (Figure 6b-d). It can be deduced that the optimized laser nitriding process gave low temperature and energy input to the sample surface, and the nitrided samples had considerably similar surface with the highest maximum peak heights $(\mathrm{H} 1)$ of $2.29 \pm 0.95 \mu \mathrm{m}$ comparing with the polished sample which had maximum peaks heights of $1.15 \pm 0.17 \mu \mathrm{m}$. Due to the slight increase in maximum peak heights over the laser nitrided samples, the highest surface roughness $(324.59 \pm$ $23.27 \mathrm{~nm}$ ) was being obtained with $1 \mathrm{~mm}$ hatch sample (H1) as well. It can be observed from the Table 5 that the patterned samples ( $\mathrm{H} 1$ and $\mathrm{H} 3$ ) had larger surface roughness values in comparison to the polished sample and wholly nitrided sample (WN). This can be attributed to the hatch patterns which had discrete TiN coating and untreated surface of the sample following the single pass of the laser beam which induced a periodic pattern causing a slight increase of surface roughness. However, the WN sample was irradiated more by the laser giving rise to an increase of surface area being coated with more homogenous TiN layer without any uncoated surface. That is, on account of significantly more TiN formation taking place, the WN sample had slightly increased of surface roughness $R_{a}$ and maximum peaks heights which had increase around $29 \mathrm{~nm}$ and $0.15 \mu \mathrm{m}$.

\subsection{Wear Resistance}

Wear resistance of the NiTi articulating implants is an important factor for its service life in hard tissue replacement $[22,33]$. Billions of microscopic particles can be created during the movement of artificial joints. Titanium nitride is becoming one of the most widely used wear resistant materials which, formed on the Ti alloys' surface, could reduce cracking and spallation and avoid the rapid failure during the motion [34, 35]. On account of this, it is an attractive material which has contributed to the enhancement of wear resistance. Nolan et al. [35] found that the TiN coated Ti-6Al-4V could minimize the wear under all normal loads situation and demonstrate the beneficial effect of Ti-6Al-4V substrate hardening. 
Figure 7 depicts the friction coefficient of nitrided and polished samples as the function of sliding cycles. The friction coefficient of polished NiTi was characterized by a rapid increase to 0.14 within the first few sliding cycles at the beginning of the test, and then gradually increased to 0.26 and reached to 0.24 at the end of the test. Comparing with the friction coefficient of polished sample, both wholly nitrided (i.e. WN sample) and partially nitrided samples (i.e. H1 and H3 samples) increased slightly after several number of sliding cycles and finally reached relatively constant values. The obtained low values of friction coefficient are typical for TiN coatings sliding against UHMWPE [36]. Both wholly and partially nitrided samples were not worn off too much due to the friction coefficient of these samples were not at the same level with that of polished sample at the final stage. Therefore, the wear resistance of wholly and partially nitrided NiTi was better than that of polished NiTi as the lower friction coefficient and wear factor (see Figure 7 and 8).

Figure 8 shows the wear factor obtained from the sliding contacts of UHMWPE pin against the laser nitrided and polished NiTi surfaces. After the laser nitriding, the wear factors of nitrided samples are lower for overall tribosystem, and the trend is more clearly observed in UHMWPE. For the case of NiTi, the wear factor decreased by $43.51 \%$ (H3 sample), $87.43 \%$ (H1 sample) and $98.17 \%$ (WN sample) on average after the nitriding process. There is a significant improvement of the wear resistant properties by laser nitriding which is supported by the discrete error bars existence and $\mathrm{P}$ value $(<0.05)$ of the comparison between polished and nitrided samples. The wholly and partially nitrided samples demonstrated smaller variations in the wear factors which implied the laser nitriding could implement the wear properties of NiTi becoming more stable and reproducible. Moreover, worn surface along the sliding tracks as revealed by the optical images shown in Figure 9 are clearly visible from both the polished and nitrided NiTi after the wear tests. Under the same wear condition, the polished sample demonstrated the formation of delaminated craters on the surface with severe worn off and more roughened surface can be observed. However, the wholly nitrided sample only presented few shallow sliding tracks without any cracks, flakes or fragmentation in the worn zone which support the improvement in the anti-wear properties of $\mathrm{NiTi}$ samples by the laser nitriding. This can be ascribed to the formation of a hard surface layer on top of the NiTi and this behavior also can be attributed to high coating toughness which was confirmed by qualitative indentation tests conducted in our previous research [28]. In addition, the higher wear rate on the polished NiTi (smoothest sample, see table 5) compared to the partially nitrided samples (rougher samples) can be explained in the following approach. The same condition with same amount of energy is dissipated in the wear test, the large amount of the energy is used for asperity deformation and laser induced patterning ridges deformation on the rougher samples (H1 and H3 samples), whilst almost all energy was used for the grooves and craters formation on the polished sample surface. The difference in the wear rates 
resulted in different wear mechanisms of each tested samples. The abrasion was the dominant wear mechanism on the smoothest sample (i.e. polished sample), whilst ridge deformation and mild abrasion were performed on the rougher samples (i.e. WN, H1 and H3 samples). Moreover, an adhesive wear is not considered as a major wear mode due to the mild loading and low contact pressure applied (i.e. around $2 \mathrm{MPa})$. Although the Hanks' solution $\left(\mathrm{Cl}^{-}\right.$ion contained) was used as simulated body fluid in the wear test and it might induce pitting attack to the tested sample surface, no pitting was observed from both polished and nitrided samples. So the corrosive wear cannot be classified in the current wear mode.

For the case of UHMWPE, the reduction in the wear factors by the laser nitriding is even more evident (i.e. $68.26 \%$ (H3 sample), $84.51 \%$ (H1 sample) and $96.61 \%$ (WN sample)). It is related to the wear resistant properties improvement of the counter surface. According to the previous studies of Ti-based alloys (i.e. Pure Ti and Ti-6Al-4V) sliding against UHMWPE, various surface treatments were implemented to enhance the wear performance of both sliding materials in the tribosystem, such as oxygen diffusion [37], thermal oxidation [37] or ion implantation [38]. Although the wear mechanism were different, the main reasons related to the wear resistant improvement in the above-mentioned studies are the formation of hard surface layer and the wettability of the target materials enhanced [29, 38]. Consequently, the enhanced efficiency of lubrication relates to the presence of pressed water film between the tribological pair, this film results in low wear rate and low friction coefficient for both titanium metallic surface and UHMWPE. From the previous study [28], the wettability of the NiTi is improved by the laser nitriding as a result of nitride film formed on the surface and is mainly responsible for the reduced wear factor of UHMWPE. Overall, the laser formed TiN layer is ultimately responsible for the improved wear resistance of the tribopair composed of NiTi and UHMWPE. What is more, whilst laser gas nitriding did give rise to an enhancement in wear resistance of the substrate, there have been an evidence to suggest that there is a correlation between the promotion of wear resistance and the percentage of TiN coverage (see Figure 8). It is obvious that the laser processing time was increasing, the percentage of TiN coverage was also increasing as well as the significant improvement of wear resistance. However, in the view of manufacturing efficiency, the production for fully nitrided surface consumes many resources, namely time, electricity and nitrogen gas. Consequently, the partially nitrided surface might be an alternative solution which could balance the advantage of manufacturing efficiency and the wear resistance enhancement. The $\mathrm{H} 1$ sample with $76 \%$ TiN coverage might be the optimal condition for the artificial joint due to it could save 59\% of laser processing time comparing with that of the fully nitrided sample (WN sample) and the reduction in the wear factor of $\mathrm{H} 1$ sample was over $80 \%$ on average for both tribopair surface. However, the existing findings should be carefully applied in the deduction to orthopaedic prostheses. The loading force employed, the type of experimental set-up, the 
testing condition and the length of experimentation do not fully correspond to those experienced by artificial joints (e.g. hip joints, knee joints) inside the body. On account of this, more relevant experimentation is necessary and further work should be continued in this area to further ascertain the feasibility in orthopaedic applications.

\section{Conclusions}

Through the Taguchi optimization of laser diffusion gas nitriding it has been shown that a uniform modification of the surface topography and surface properties can be brought about in NiTi. That is, by using a simple but effective hatch pattern, a fibre laser can create variations in TiN coverage as well as small changes of surface roughness of up to $325 \mathrm{~nm}$, giving rise to an enhancement of the wear characteristics. Hence, the following conclusions could be drawn:

1. With the nitrogen gas flow rate fixed at $40 \mathrm{~L} / \mathrm{min}$ in the Taguchi optimization study, the optimal laser power was found to be $90 \mathrm{~W}$, laser scanning speed and the beam diameter are 1 $\mathrm{mm} / \mathrm{s}$ and $2.2 \mathrm{~mm}$ respectively which is to create a uniform and non-roughen TiN layer on NiTi surface.

2. The partially nitrided sample with $76 \%$ TiN coverage may be an alternative suggestion for the surface hardening and wear resistance enhancement of the artificial joint comparing with fully nitrided method due to $59 \%$ of laser processing time being saved.

With an aging worldwide population there is an ever growing demand for a higher quality of life. As a result of this, the need is ever increasing for new technologies which can be beneficial for the biomedical industries and this demand is very much seen in the field of orthopaedic replacements. On account of precision and the ease of automation of the fibre laser gas nitriding process discussed here, it can be seen as an attractive and effective means for modifying NiTi articulating implant materials and improving the tribological properties of tribo-pairs.

\section{Acknowledgement}

The work was supported by the visiting research associateship provided by the School of Mechanical and Aerospace Engineering, Queen's University, Belfast, UK, and by the Hong Kong Polytechnic University, Hong Kong Special Administration Region, China research (Grant Nos. G-YK36 and G-YM75). The PhD funding from University of Chester, UK as international studentship is gratefully acknowledged. 


\section{References}

[1] Kurtz S, Ong K, Lau E, Mowat F, Halpern M. Projections of primary and revision hip and knee arthroplasty in the United States from 2005 to 2030. The Journal of bone and joint surgery American volume. 2007;89:780-5.

[2] Long M, Rack HJ. Titanium alloys in total joint replacement - a materials science perspective. Biomaterials. 1998;19:1621-39.

[3] Semlitsch M. Titanium alloys for hip joint replacements. Clinical Materials. 1987;2:1-13. [4] Mihalc I. Fundamental characteristics and design method for nickel-titanium shape memory alloy. Periodica Polytechnica Mechanical Engineering. 2001;45:75-86.

[5] Bahraminasab M, Jahan A. Material selection for femoral component of total knee replacement using comprehensive VIKOR. Materials \& Design. 2011;32:4471-7.

[6] Khan MA, Williams RL, Williams DF. Conjoint corrosion and wear in titanium alloys. Biomaterials. 1999;20:765-72.

[7] Man HC, Zhao NQ. Phase transformation characteristics of laser gas nitrided NiTi shape memory alloy. Surface and Coatings Technology. 2006;200:5598-605.

[8] Man HC, Bai M, Cheng FT. Laser diffusion nitriding of Ti-6Al-4V for improving hardness and wear resistance. Applied Surface Science. 2011;258:436-41.

[9] Schaaf P, Kaspar J, Höche D. 9.13 - Laser Gas-Assisted Nitriding of Ti Alloys A2 Hashmi, Saleem. In: Batalha GF, Tyne CJV, Yilbas B, editors. Comprehensive Materials Processing. Oxford: Elsevier; 2014. p. 261-78.

[10] Yilbas BS, Karatas C, Uslan, Keles O, Usta IY, Ahsan M. CO2 laser gas assisted nitriding of Ti-6Al-4V alloy. Applied Surface Science. 2006;252:8557-64.

[11] Jianglong L, Qiquan L, Zhirong Z. Laser gas alloying of titanium alloy with nitrogen. Surface and Coatings Technology. 1993;57:191-5.

[12] Waugh DG, Lawrence J. Laser Surface Engineering: Processes and Applications. Cambridge, UK: Elsevier Ltd; 2015.

[13] Vaz F, Cerqueira P, Rebouta L, Nascimento SMC, Alves E, Goudeau P, et al. Structural, optical and mechanical properties of coloured TiNxOy thin films. Thin Solid Films. 2004;447-448:449-54.

[14] Chu PK, Chen JY, Wang LP, Huang N. Plasma-surface modification of biomaterials. Materials Science and Engineering: R: Reports. 2002;36:143-206.

[15] Chan CW, Hussain I, Waugh DG, Lawrence J, Man HC. Effect of laser treatment on the attachment and viability of mesenchymal stem cell responses on shape memory NiTi alloy. Materials science \& engineering C, Materials for biological applications. 2014;42:254-63. [16] Silva MM, Pichon L, Drouet M, Otubo J. Roughness studies of NiTi shape memory alloy treated by nitrogen plasma based ion implantation at high temperatures. Surface and Coatings Technology. 2012;211:209-12.

[17] Lin N, Huang X, Zou J, Zhang X, Qin L, Fan A, et al. Effects of plasma nitriding and 
multiple arc ion plating TiN coating on bacterial adhesion of commercial pure titanium via in vitro investigations. Surface and Coatings Technology. 2012;209:212-5.

[18] Fu Y, Wu X, Wang Y, Li B, Yang S-z. Study of corrosion resistance property and microstructure of TiNi shape memory alloy modified by pulsed high-energy density plasma. Applied Surface Science. 2000;157:167-77.

[19] Li B, Wang X, Min Y, Liang C, Li H, Guo L, et al. Corrosion resistance and mechanical properties of titanium with hierarchical micro-nanostructure. Materials Letters.

2016;182:43-6.

[20] Zhang J, Xue Q, Li S. Microstructure and corrosion behavior of TiC/Ti(CN)/TiN multilayer CVD coatings on high strength steels. Applied Surface Science. 2013;280:626-31. [21] Naghibi SA, Raeissi K, Fathi MH. Corrosion and tribocorrosion behavior of Ti/TiN PVD coating on 316L stainless steel substrate in Ringer's solution. Materials Chemistry and Physics. 2014;148:614-23.

[22] Shabalovskaya SA. Surface, corrosion and biocompatibility aspects of Nitinol as an implant material. Bio-medical materials and engineering. 2002;12:69-109.

[23] Zhecheva A, Sha W, Malinov S, Long A. Enhancing the microstructure and properties of titanium alloys through nitriding and other surface engineering methods. Surface and Coatings Technology. 2005;200:2192-207

[24] Man HC, Cui ZD, Yue TM. Surface characteristics and corrosion behavior of laser surface nitrided NiTi shape memory alloy for biomedical applications. Journal of Laser Applications. 2002;14:242-7.

[25] Peace G. Taguchi Methods: A Hands on Approach. Harlow, USA: Addison Wesley Publishing Company, Inc.; 1992.

[26] Antony J, Antony FJ. Teaching the Taguchi method to industrial engineers. Work Study. 2001;50:141-9.

[27] Nalbant M, Gökkaya H, Sur G. Application of Taguchi method in the optimization of cutting parameters for surface roughness in turning. Materials \& Design. 2007;28:1379-85. [28] Ng CH, Chan OK, Man HC. Formation of TiN Grid on NiTi by Laser Gas Nitriding for Improving Wear Resistance in Hanks' Solution. Journal of Materials Science \& Technology. 2016;32:459-64.

[29] Xiong D, Gao Z, Jin Z. Friction and wear properties of UHMWPE against ion implanted titanium alloy. Surface and Coatings Technology. 2007;201:6847-50.

[30] Statistical methods for research workers. By Sir Ronald A. Fisher. Edinburgh (Oliver and Boyd), 12th Ed., 1954. Pp. xv, 356; 12 Figs., 74 Tables. 16s. Quarterly Journal of the Royal Meteorological Society. 1956;82:119-.

[31] Xavior MA, Yarlagadda PKDV, Venkatesan K, Ramanujam R, Kuppan P. "12th Global Congress on Manufacturing and Management" GCMM - 2014Analysis of Cutting Forces and Temperature in Laser Assisted Machining of Inconel 718 Using Taguchi Method. Procedia 
Engineering. 2014;97:1637-46.

[32] Bernard SA, Balla VK, Davies NM, Bose S, Bandyopadhyay A. Bone cell-materials interactions and $\mathrm{Ni}$ ion release of anodized equiatomic NiTi alloy. Acta Biomater.

2011;7:1902-12.

[33] Bansiddhi AS, T.D.; Stupp, S.I.; Dunand, D.C. Porous NiTi for bone implants: A review. Acta Biomaterialia. 2008;4:773-82.

[34] Starosvetsky D, Gotman I. Corrosion behavior of titanium nitride coated Ni-Ti shape memory surgical alloy. Biomaterials. 2001;22:1853-9.

[35] Nolan D, Huang SW, Leskovsek V, Braun S. Sliding wear of titanium nitride thin films deposited on Ti-6Al-4V alloy by PVD and plasma nitriding processes. Surface and Coatings Technology. 2006;200:5698-705.

[36] Galvin A, Brockett C, Williams S, Hatto P, Burton A, Isaac G, et al. Comparison of wear of ultra-high molecular weight polyethylene acetabular cups against surface-engineered femoral heads. Proceedings of the Institution of Mechanical Engineers Part H, Journal of engineering in medicine. 2008;222:1073-80.

[37] Shi W, Dong H, Bell T. Tribological behaviour and microscopic wear mechanisms of UHMWPE sliding against thermal oxidation-treated Ti6A14V. Materials Science and Engineering: A. 2000;291:27-36.

[38] Dong H, Shi W, Bell T. Potential of improving tribological performance of UHMWPE by engineering the Ti6A14V counterfaces. Wear. 1999;225-229, Part 1:146-53. 


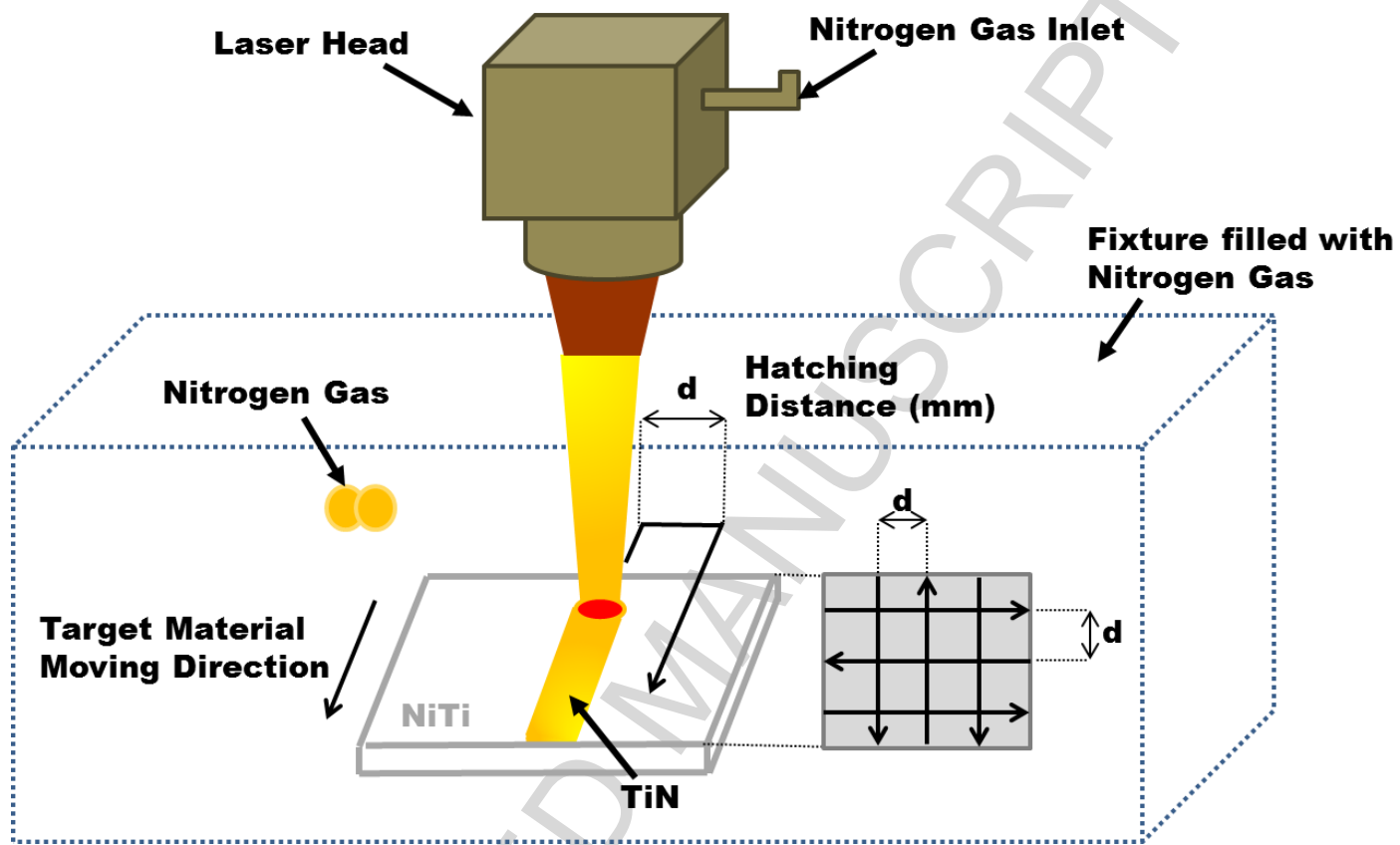

Figure 1: Schematic diagram showing the laser set-up and scanning patterns. 


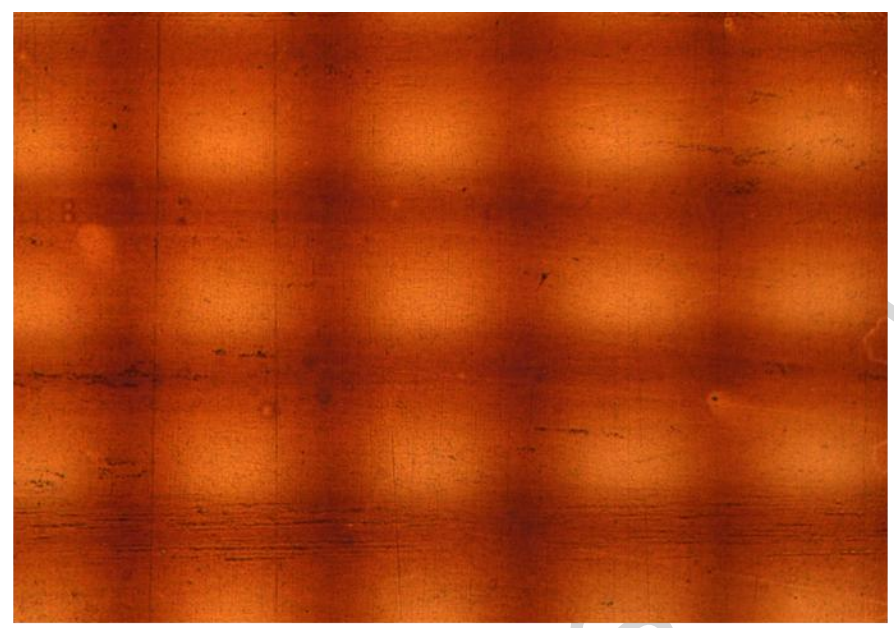

(a) Optical micrograph of the $\mathrm{H} 1$ laser induced pattern before ImageJ analysis

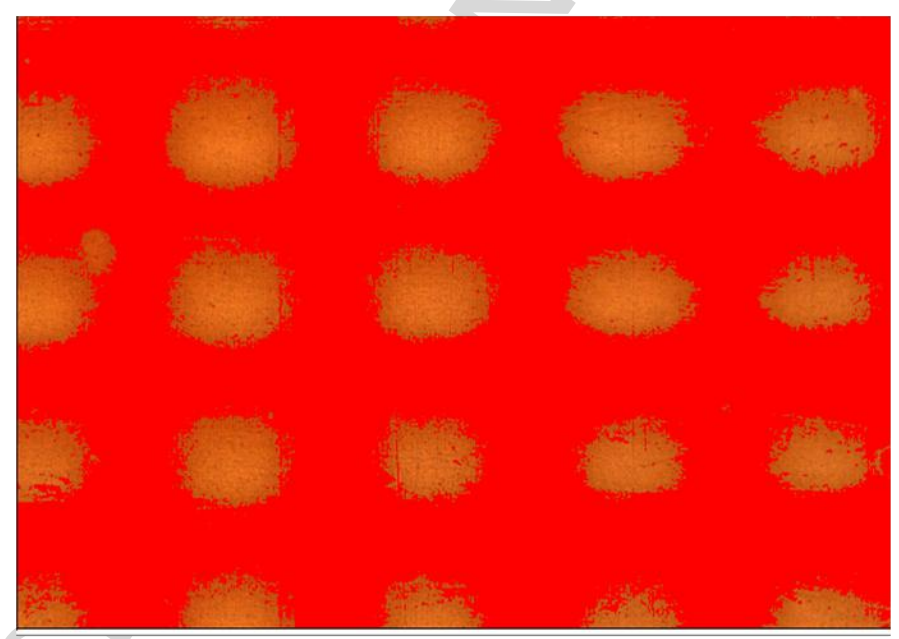

(b) Optical micrograph of the $\mathrm{H} 1$ laser induced pattern after ImageJ analysis

Figure 2: Example of the ImageJ measurement on the laser nitrided samples. 


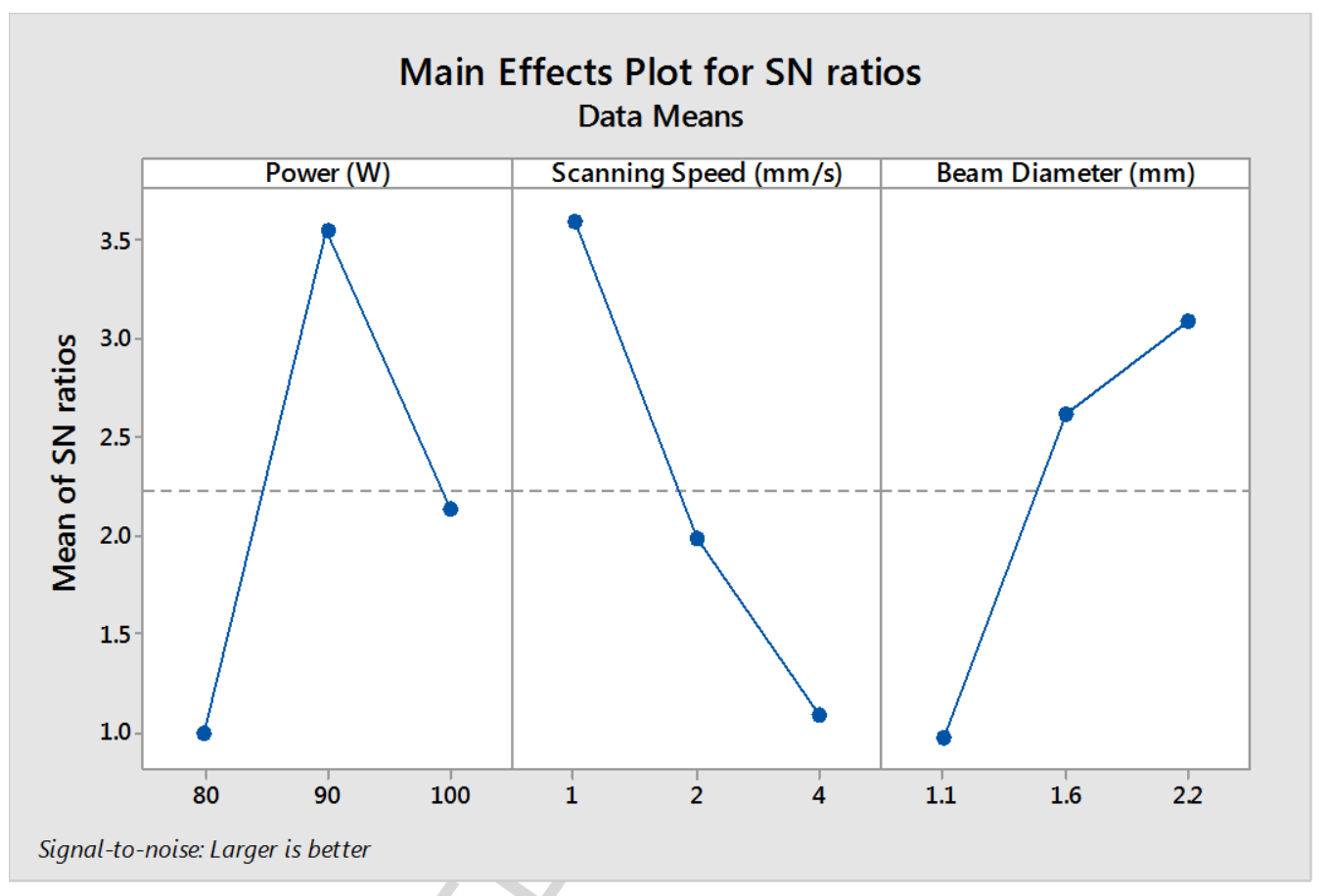

Figure 3: Means of the S/N ratios for each laser parameter. 


\section{TiN}

\section{$20 \mathrm{kV} \quad \mathrm{X} 2,000 \quad 10 \mu \mathrm{m} \quad 1150$ SEI}

Figure 4: SEM micrograph showing the cross-section view of TiN layer. 


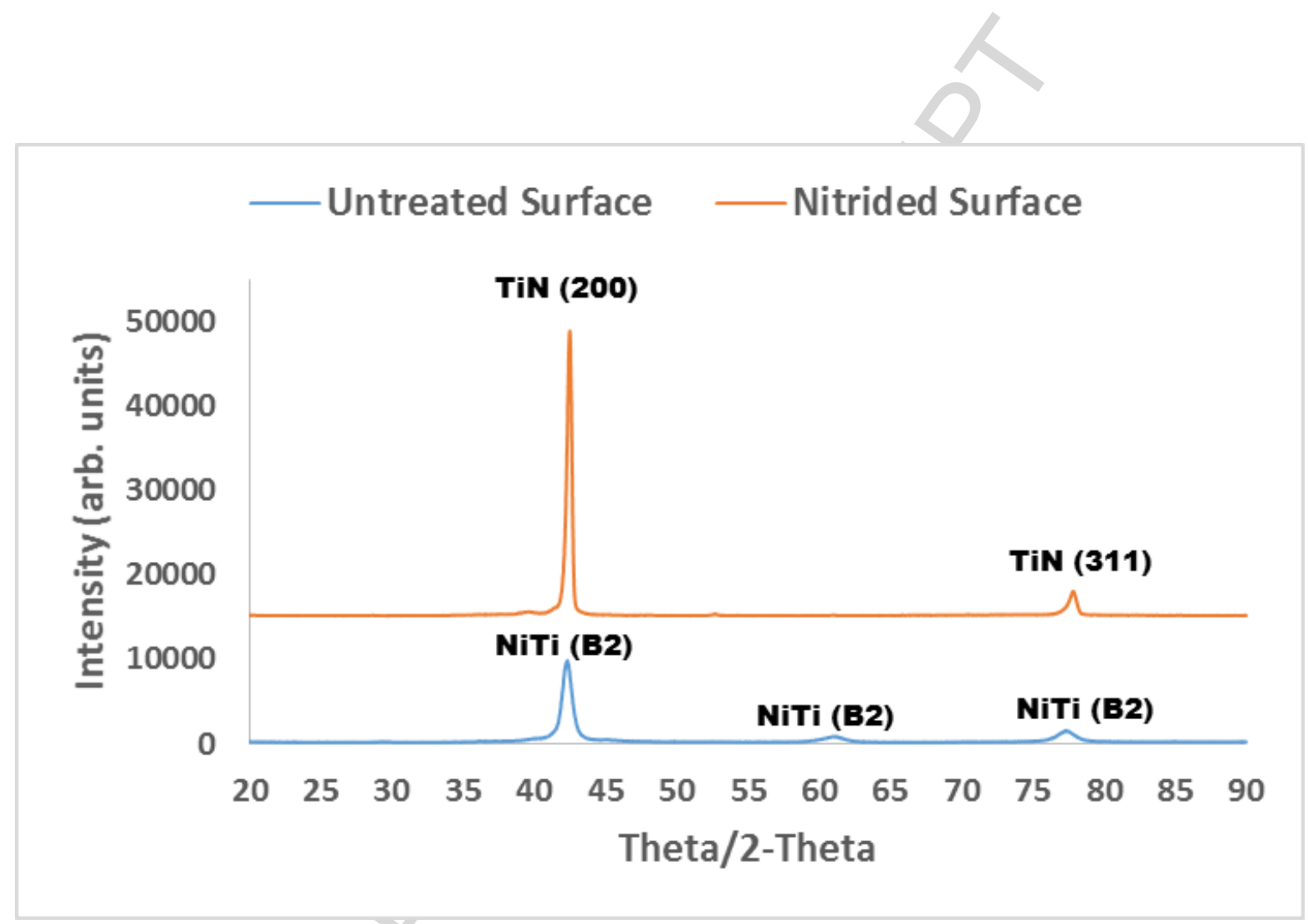

Figure 5: XRD spectra for a laser nitrided and untreated surface. 


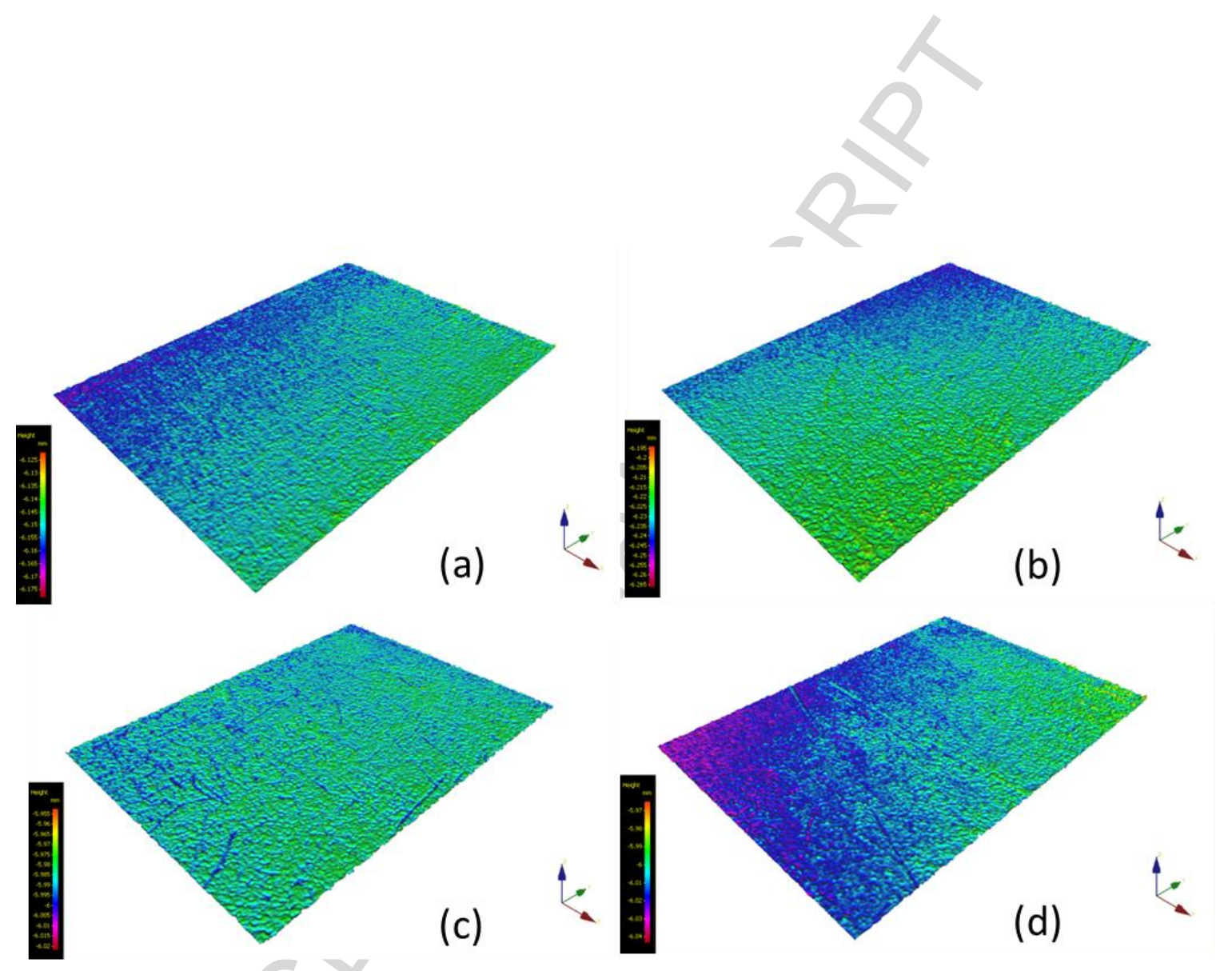

Figure 6: 3-D profiles for (a) polished (b) WN (c) H1 and (d) H3 samples. 


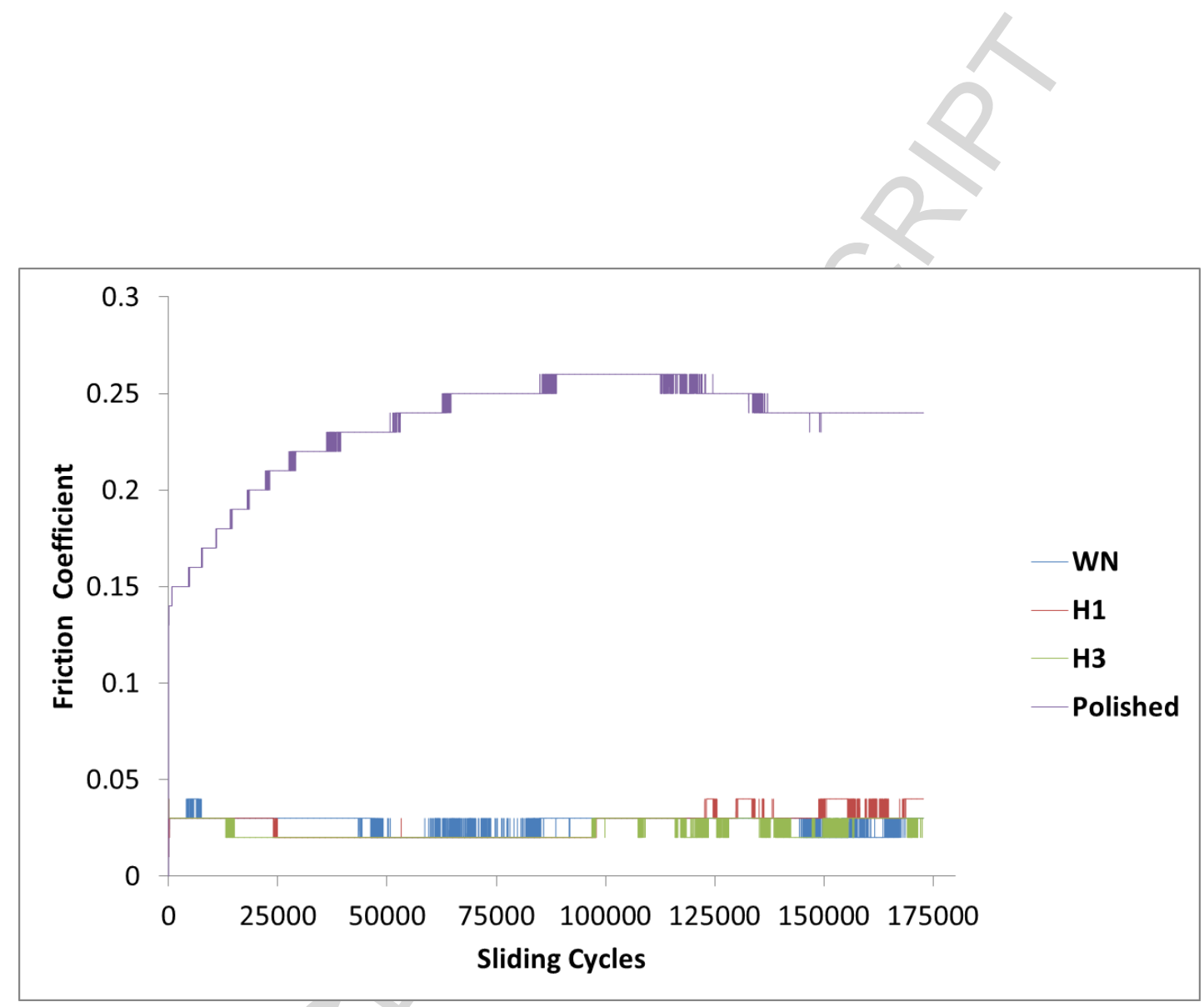

Figure 7: Frictional curves of polished, WN, H1 and H3 samples. 


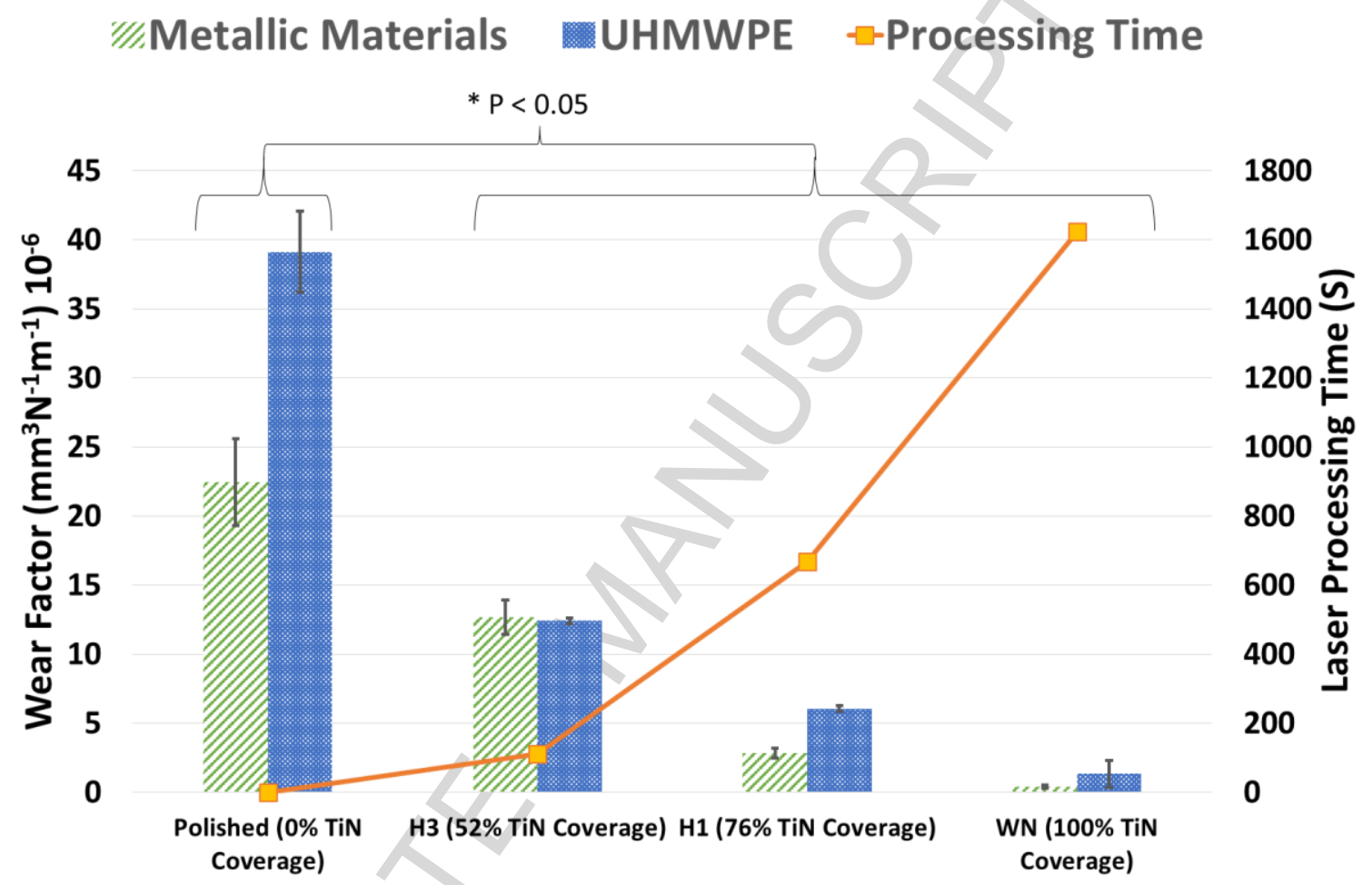

Figure 8: Wear factor for each sample in relation to laser processing time. * Probability values of $P<0.05$ were considered indicative of significant difference. 

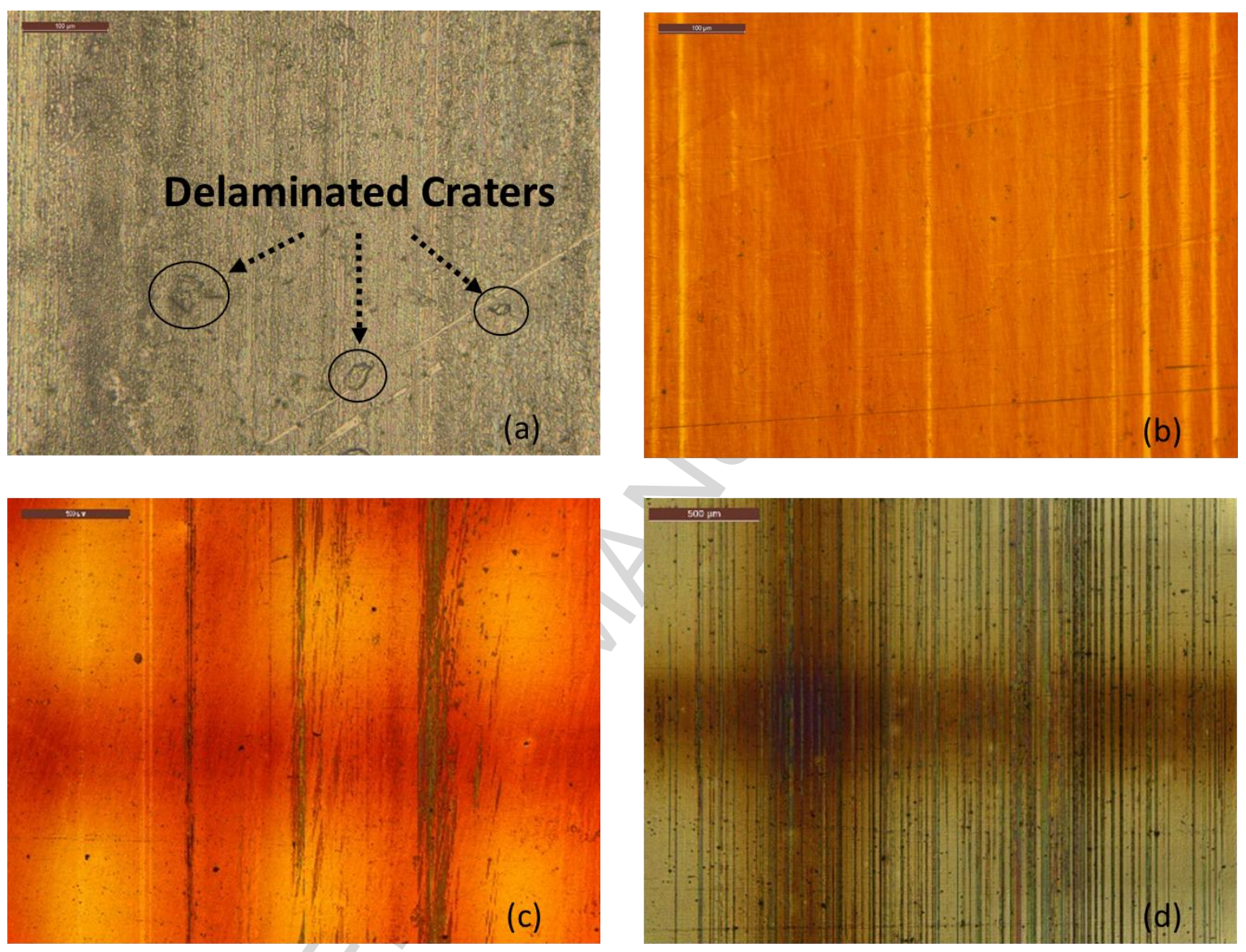

Figure 9: Optical micrographs of the surface of (a) polished, (b) WN, (c) H1 and (d) H3 samples after the wear test. 
Table 1: Levels of each laser parameter

\begin{tabular}{cccc}
\hline & Level 1 & Level 2 & Level 3 \\
\hline Power $(\mathrm{W})$ & 80 & 90 & 100 \\
Scanning Speed $(\mathrm{mm} / \mathrm{s})$ & 1 & 2 & 4 \\
Beam diameter $(\mathrm{mm})$ & 1.1 & 1.6 & 2.2 \\
\hline
\end{tabular}


Table 2: Results for the width of TiN coverage and calculated S/N ratio.

\begin{tabular}{cccccc}
\hline Run & $\begin{array}{c}\text { Power } \\
(\mathrm{W})\end{array}$ & $\begin{array}{c}\text { Scanning } \\
\text { Speed } \\
(\mathrm{mm} / \mathrm{s})\end{array}$ & $\begin{array}{c}\text { Beam } \\
\text { Diameter } \\
(\mathrm{mm})\end{array}$ & $\begin{array}{c}\text { Measured Width } \\
\text { of laser track } \\
(\mathrm{mm})\end{array}$ & $\begin{array}{c}\text { Calculated S/N ratio } \\
\text { (Larger-the-better) }\end{array}$ \\
\hline 1 & 80 & 1 & 1.1 & 1.00 & -0.02 \\
2 & 80 & 2 & 1.6 & 1.23 & 1.79 \\
3 & 80 & 4 & 2.2 & 1.14 & 1.06 \\
4 & 90 & 1 & 1.6 & 1.94 & 5.75 \\
5 & 90 & 2 & 2.2 & 1.42 & 3.02 \\
6 & 90 & 4 & 1.1 & 1.24 & 1.83 \\
7 & 100 & 1 & 2.2 & 1.79 & 5.01 \\
8 & 100 & 2 & 1.1 & 1.13 & 1.08 \\
9 & 100 & 4 & 1.6 & 1.03 & 0.22 \\
\hline
\end{tabular}


Table 3: Analysis of the variance for $S / N$ ratio of different laser parameter.

Percent Contribution,

\begin{tabular}{ccccccc} 
Source & DF & Seq SS & Adj SS & Adj MS & F & P \\
\hline Power $(\mathrm{W})$ & 2 & 10.14 & 10.14 & 5.07 & 1.75 & 30.54 \\
Scanning Speed & & & & & & \\
$(\mathrm{mm} / \mathrm{s})$ & 2 & 10.05 & 10.05 & 5.03 & 1.73 & 30.29 \\
Beam Diameter (mm) & 2 & 7.20 & 7.20 & 3.60 & 1.24 & 21.68 \\
Residual Error & 2 & 5.80 & 5.80 & 2.90 & & 17.48 \\
Total & 8 & 33.19 & & & & \\
\hline
\end{tabular}


Table 4: Response table for S/N ratio of different laser parameter.

\begin{tabular}{cccc}
\hline Level & Power $(\mathrm{W})$ & $\begin{array}{c}\text { Scanning Speed } \\
(\mathrm{mm} / \mathrm{s})\end{array}$ & $\begin{array}{c}\text { Beam Diameter } \\
(\mathrm{mm})\end{array}$ \\
\hline 1 & 0.94 & $3.60^{*}$ & 0.96 \\
2 & $3.54^{*}$ & 1.96 & 2.59 \\
3 & 2.12 & 1.04 & $3.05^{*}$ \\
Delta & 2.60 & 2.56 & 2.08 \\
Rank & 1 & 2 & 3 \\
\multicolumn{2}{l}{ Total mean of S/N ratio $=2.20 ;$ * Optimized level of parameters } \\
\hline
\end{tabular}


Table 5: Table showing the surface roughness, area coverage of nitrided and untreated area across target material.

\begin{tabular}{|c|c|c|c|c|}
\hline Sample & $\mathrm{R}_{\mathrm{a}}(\mathrm{nm})$ & $\mathrm{R}_{\mathrm{p}}(\mu \mathrm{m})$ & $\begin{array}{l}\text { Nitrided Area } \\
\text { coverage }\end{array}$ & Untreated Area Coverage \\
\hline $\mathrm{WN}$ & $277.23 \pm 28.60$ & $\begin{array}{c}1.30 \pm \\
0.21\end{array}$ & $100 \%$ & $0 \%$ \\
\hline $\mathrm{H} 1$ & $324.59 \pm 23.27$ & 0.95 & $76 \%$ & $24 \%$ \\
\hline $\mathrm{H} 3$ & $322.23 \pm 45.74$ & & $52 \%$ & $48 \%$ \\
\hline Polished & $248.03 \pm 26.09$ & 0.17 & $0 \%$ & $100 \%$ \\
\hline
\end{tabular}


NiTi shape memory alloy with enhanced wear performance by laser selective area nitriding for orthopaedic applications

\section{$\underline{\text { Research Highlights }}$}

- L9 Taguchi experiment employed to optimize laser gas nitriding process.

- Laser gas nitriding of NiTi gave rise to enhanced wear characteristics.

- Laser surface engineering applied to enhance surface properties of biomaterials. 